\title{
Combination of two non-prescription eye drops for early cortical cataracts
}

\begin{abstract}
$\mathrm{N}$-acetyl carnosine (NAC) drops have been proposed for the treatment of age-related cataracts but "[t]here is currently no convincing evidence that NAC reverses cataract." A 2019 study failed to improve cataracts using lanosterol. ${ }^{2}$ Dimethyl sulfoxide (DMSO) decreases ocular inflammation ${ }^{3}$ and it is a well-known carrier.
\end{abstract}

Volume 14 Issue 3 - 202I

\section{Manuel Moran}

Department of Surgery, Veterans Administration Medical Center, USA

\author{
Correspondence: Manuel Moran, 480 IVeterans Drive, \\ Veterans Administration Medical Center, USA, Saint Cloud, MN \\ 56303, USA, Tel I-320-255-6429, Fax I-320-255-6406, \\ Email Manuel.Moran@va.gov
}

Received: May 22, 2021 | Published: June 08, 2021

\section{Letter to editor}

The issue is whether adding the carrier dimethyl sulfoxide to other eye drops, like lanosterol or N-acetyl carnosine, will allow for dissolution of early cataracts. About 5-6 years ago, my optometrist diagnosed me with "early cortical cataracts." One or two years later I improved my diet, switching to an organic mostly plant-based diet. Later, I changed eye clinics and saw two different optometrists. The cataract diagnosis was confirmed. On two different occasions, I used Can- $C^{\circledR}(1 \% \mathrm{~N}$-acetyl carnosine) drops daily for one-two months before my next annual optometry exam. My cataracts did not change. Recently, I decided to use a combination of drops three times daily for two months before my eye exam. Left eye was treated with one drop of Cataract Clear ( $4.2 \% \mathrm{~N}$-acetyl carnosine) immediately followed by one drop of $40 \%$ DMSO Eye Drops ${ }^{\circledR}$ in normal saline (dimethyl sulfoxide from YumNaturals). Right eye was treated with one drop of Lanomax ${ }^{\circledR}$ (lanosterol $2 \mathrm{mg} / \mathrm{ml}$ ) immediately followed by one drop of $40 \%$ DMSO. A less concentrated DMSO eye drops is available and produces less eye irritation or burning sensation, but I assumed the $40 \%$ DMSO was going to be diluted to about $20 \%$ by the previously applied drops. Lanomax ${ }^{\circledR}$ is commercially available without a prescription to treat cataracts in animals. I recently went back to the first ophthalmology clinic and was seen by the optometrist who made the initial cataract diagnosis. Just before the eye exam, I told the optometrist he had diagnosed me with cataracts years ago but because of my very healthy diet I might not have cataracts any longer. The optometrist disagreed with me and stated cataracts are normal in my age group (62 years old) and he also said cataracts "do not go away". Despite his assertive statement, the optometrist admitted at the end of the eye exam that I did not have any cataracts. He mentioned a yellowish tint but both crystalline lenses were clear of cataracts.

Lanomax ${ }^{\circledR}$ has been found to clear cataracts in dogs when injected intraocularly. Eye drops do not work as well because of their inadequate absorption into the lens. DMSO is a well-known carrier; it greatly facilitates dermatological absorption of medications applied on the skin. My hypothesis assumed DMSO should be an effective carrier for eye drops and, if so, cataracts should be reversable. It seemed to be effective, at least in part, with several condition accompanied in my case. A detail follow-up will also be necessary for further investigation from a pathophysiological point of view.

Maybe people who have reached a certain age should be prophylactically treated with a combination of eye drops even before they develop early cataracts. And surely once early cataracts have been diagnosed.

\section{Conclusion}

The combination of (a) $40 \% \mathrm{DMSO}+4.2 \% \mathrm{~N}$-acetyl carnosine or (b) $40 \%$ DMSO + lanosterol completely dissolved early cortical cataracts in one person.

\section{Acknowledgments}

None.

\section{Conflicts of interest}

Author declares there are no conflicts of interest.

\section{Funding}

None.

\section{References}

1. Dubois V, Bastawrous A. N-acetylcarnosine (NAC) drops for age-related cataract. Cochrane Database Syst Rev. 2017;2(2):CD009493.

2. Daszynski DM, Santhoshkumar P, Phadte AS. et al. Failure of Oxysterols Such as Lanosterol to Restore Lens Clarity from Cataracts. Sci Rep. 2019;9:8459.

3. Hanna C, Fraunfelder FT, Meyer SM. Effects of dimethyl sulfoxide on ocular inflammation. Ann Ophthalmol. 1977;9(1):61-65. 